\title{
Business Process Reengineering: A Scope of Automation in Software Project Management using Artificial Intelligence
}

\author{
Krunal Bhavsar, Vrutik Shah, Samir Gopalan
}

\begin{abstract}
This research paper aims an analytical study on the software development organization insight into trending automation technologies and their implementation Software Engineering Management (SEM) processes. Software Project Management (SPM) is a scientific art for planning, controlling execution and monitoring. SPM approaches are more focusing towards the essential requirement for the success of software project development. It has been very challenging to manage software development using existing project management procedures driven by software development organizations and this is one of the areas of problem statement for this research. This paper discusses an analytical study for the requirements and consideration of BPR in SPM, explores to spot and emphasizes the important success factors for the execution of a BPR using benefits of Artificial Intelligence (AI) in software development organization. BPR is organizational mechanism that improves ability to respond to challenges of qualitative result by change and improvement in software engineering processes, productivity, product quality and competitive advantages. AI will be the best approach and scope of automation SEM processes for software development organizations. This paper also represents a conceptual view of software engineering model shift for improvements in capability of project managers to handle agile thinking and problem solving for betterment of SPM using Artificial Intelligence.
\end{abstract}

Keywords : AI - Artificial Intelligence, BPR - Business Process Reengineering, BPM - Business Process Management, SE Software Engineering, SEM - Software Engineering Management, SPM - Software Process Management, SPI Software Process Improvement

\section{INTRODUCTION}

Artificial Intelligence (AI) is a sub domain of computer science and technology engineering domains that spotlights

Revised Manuscript Received on December 30, 2019.

* Correspondence Author

Krunal Bhavsar*, Department of Computer Science and Engineering, Indus University, Ahmedabad, Gujarat, India. Email: krunalbhavsar@engineer.com; krunalbhavsar.rs@indusuni.ac.in. Contact: +91-9737007007.

Dr. Vrutik Shah, Research Guide, Department of Computer Science \& Engineering, Indus University, Ahmedabad, India.

Dr. Samir Gopalan, Research Co-Guide, Business Administration \& Management, Indus University, Ahmedabad, India.

(C) The Authors. Published by Blue Eyes Intelligence Engineering and Sciences Publication (BEIESP). This is an open access article under the CC BY-NC-ND license (http://creativecommons.org/licenses/by-nc-nd/4.0/) the invention of intelligence and machines learning that perform all operations like natural humans and SPM

(Software Project Management) is a strategy for software business organization which includes project planning, scheduling, and resource allocation and change management. AI is trending in software development firms and has started gaining potential by software project managers. Result of software project is absolutely dependent of software development model and AI technologies used by a software development organization. Incorrect model and out dated technology may result into failure of project or compromise with predicted output of software project and also creates a risk for all types of stakeholders involved in the project, for proper understanding of requirement, project budgeting, quality control and control over of the costs of development. Change management has become an essential for an organization to compete with its own classic methodologies for organization management. New forms of organization, competitive pressures and the use of Information Systems seemed to have decreased productivity of managers. Fragmentation of existing systems and then reform them using the BPR approach. Inherently, organizations could also be able to contend with a quickly dynamical business structure, through internal amendment but AI has a power to extend the concept of process change, from fundamental hypothetical considerations and standards of software engineering process management. Project management parameters with intelligent use of software models can make software project managers capable to analyze the inherent risk, intelligent scheduling and resource management. An advancement of AI has tried to automate processes where human intervention is required for reusability of task. AI helps software development organization managers in implementing agile software development approach for the operation management and other stakeholders also.

\section{RESEARCH OBJECTIVES}

Primary and core significant aim and objective of this research study is highlight on the conceptual view for the implementation of trending automation technologies for Software Engineering Management (SEM) processes in software development organizations using following analytical studies:

- Classical SEM processes and their limitations

- Improvements in SEM processes

Published By:

Blue Eyes Intelligence Engineering \& Sciences Publication 


\section{Business Process Reengineering: A Scope of Automation In Software Project Management using Artificial}

Intelligence

- Scope of BPR using AI technologies

Automation of the processes the future of technologies and $\mathrm{AI}$ is the future of automation technology that can bring revolution in existing reengineering processes.

The qualitative analysis of SEM processes and approaches in software development organization based on literature reviews, and representation conceptualization view of the use of AI in software system development and life cycle stages, are the research methods for targeting the goal of this research.

\section{ARTIFICIAL INTELLIGENCE (AI)}

Artificial Intelligence (AI) is a sub domain of computer science field. AI approaches are cost efficient and operational, as well as more tailored in transformations of strategic business program. However there are several risks of using AI because of, limited or no availability data for analysis or required quantity of data or available data is of low quality and no or poor understanding of AI inherent risks. AI could be a theory regarding the event of learning strategy for computer systems capable to execute operations that unremarkably need intelligence of natural human power. Samples of such operations embody speech recognition, visual perception, result oriented decision making and learning beneath ambiguity. AI applications area unit able to analyze information to spot patterns and build selections supported style of patterns. They're organized and coded to find out from the information they're equipped using programming techniques, either as a natural event at the time of their style, or on endless to enhance computer systems' performance by exposure to information while not the necessity to follow expressly programmed directions of AI, trending in software development projects and organization management are:

- Machine Learning (ML)

- Deep Learning (DL)

- Speech Recognition (SR)

- Natural Language Processing (NLP)

\section{A. Machine Learning (ML)}

Machine Learning (ML) has capability of enhancement in computer systems' processes and performance by exposure to information without the requirement to follow expressively programmed algorithms. Machine Learning (ML) is a subdomain for AI and a scientific analysis of statistical models and algorithms that computer based software systems use to improve their performance on a specific work. At its core, Machine Learning (ML) is that the method of mechanically discovering patterns in information and victimization them to create predictions. ML

\section{B. Deep Learning (DL)}

Deep Learning (DL) is a branch of AI and computer science; and a subfield under ML algorithms as a function of the brain known as ANN (Artificial Neural Networks). Deep learning focuses on learning of data representation and is quite different than task-specific algorithms. Deep Learning (DL) algorithms area unit a category of ML algorithms that have become fabulous due to their effectiveness in operations associated with computer vision and speech. They're advanced techniques wherever it's onerous to decipher precisely how every input drives model outcomes, usually leading to them being recognized as "black boxes".

\section{Speech Recognition (SR)}

Speech recognition enables machines or software system to identify phrases or words in auditory communication and convert them into machine comprehendible structure. Cardinally SR (Speech Recognition) encompasses a restricted assortment of vocabulary of statement phrases and words, and it's going to solely acknowledge these if they're clearly spoken. Speech recognition is the sub-field of computational linguistics that inter-disciplinary develops methodologies and technologies that allow the recognition and translation of spoken language into text by computers.

\section{Natural Language Processing (NLP)}

Natural Language Processing (NLP) could be the subdivision of computer science and AI technologies, which enables interactions between human understandable languages and information system and defines the way to program computers to analyze and progress large amounts of data in natural language. NLP applications development is very challenging for the software engineers as a system requires a speech of human as an input to for a programming, especially when there is unambiguous and precise speech or from a restricted range of clearly vocalized commands. Natural human speech, however, isn't perpetually proper and correct. The linguistic structure in natural human vocabulary is ambiguous and might rely upon several advanced critical variables, as well as slang, regional dialects and social context.

\section{BPR WITH AI}

Integration of $\mathrm{AI}$ as a solution to Business Process Management (BPM) can build traceability and auditability as difficult, and also the speed at that they'll end in errors apparently on a large scale, in a too short time duration. BPR is focused in helping organizations to rethink about what are the issues with existing system and how to do the work in order to improve product quality, services, cut operational costs and how to face market competitions. BPR (Business process reengineering) projects are undertaken by organizations which are outward searching for important amendment within the organization performance and expecting radical changes in variables. Fundamentally, such organizations are unit trendsetters in their relative domains and market segments. BPR projects are generally large and take longer time along with significant inflow capital. BPR focuses on redesigning of organizational workflows and business processes. BPR helps organizations to restructure their processes by aiming on the bottom-up design of their business processes. According to Joshi and Dangwal ${ }^{[2]}$, BPR is one in all the foremost ubiquitous development strategies used across the world. This research study is also focusing regarding a way to conceptualize the scope of AI to seeks its implications for tradition system flow and risk management, in addition because the regulative context within software development organization.

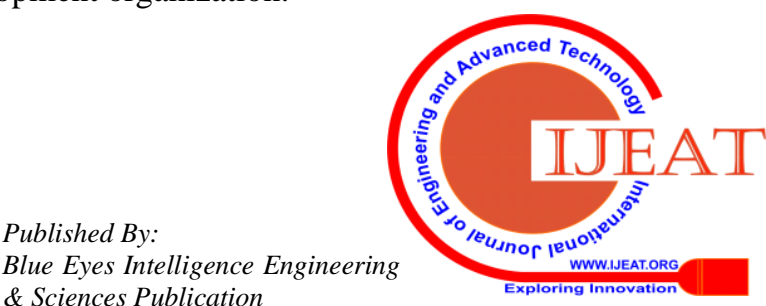


Such areas empower firm's vision to focus more effective result, face challenges and improvements in development of an AI strategy, specifically the development of a software using AI. We can analyze by reflecting on regulators to regulate $\mathrm{AI}$ and its challenges.

\section{SPM WITH AI}

Software project management is a science of software development and art of communicating with different stakeholders ${ }^{[1]}$ according to Hammer and Champy. Project management software can have following primary functions according to ISO/ICE/IEEE 12207:2017 System and Software Engineering - System Life Cycle Processes standards ${ }^{[29]}$ for software system development:

- Task Management

- Time Tracking

- Documentation

- Scheduling

- Project Planning

- Bug Reporting

- Project Development

- Delivery and Maintenance

Project management software systems are used in a several ways with the main goal, to facilitate the tracking of project phases, resources and stakeholders. SDLC (Software Development Life Cycle) is a structured way to handle software development and management using various standard SDLC models. Consistently changing technology market has been demanding business process reengineering in SDLC models also and it results into improvement in estimation of software delivery at some level of aspects but can't automate processes. Software engineering is scientific approach associated with software product development using well defined procedures, methods and engineering principles. SDLC is a kind of algorithms for making quality software system among the given time ${ }^{[28]}$. AI with software project management enables a system itself that it can perform all activities of management and administer projects without requiring human intervention. AI provides high level of services that has been growing with in the form bot applications today. Business chat-boats like Hipchat, Googlebot etc. enable an instant response to the query of users. It can develop an understanding of key project performance by automation of tasks. AI in Project management performs more complex tasks, make recommendations, can uncover insights and make decisions. A machine learning approach applied to project management helps in project scheduling and task estimation. ML based algorithms can bring potential power in hands of software project manager in achieving success for projects by implementing AI bots. So many unsuccessful software projects have been resulted in last decade and that is the reason for considerable improvements in software project management are essential ${ }^{[6]}$. The main bodies of knowledge should be determined based on Artificial Intelligence. And the same is determined by several literature reviews. Following are some of the key areas for integration of AI with SEM:

- Project Scope

- Project Estimation
- Risk Management

- Project Model

- Stakeholder Integration

- Controlling

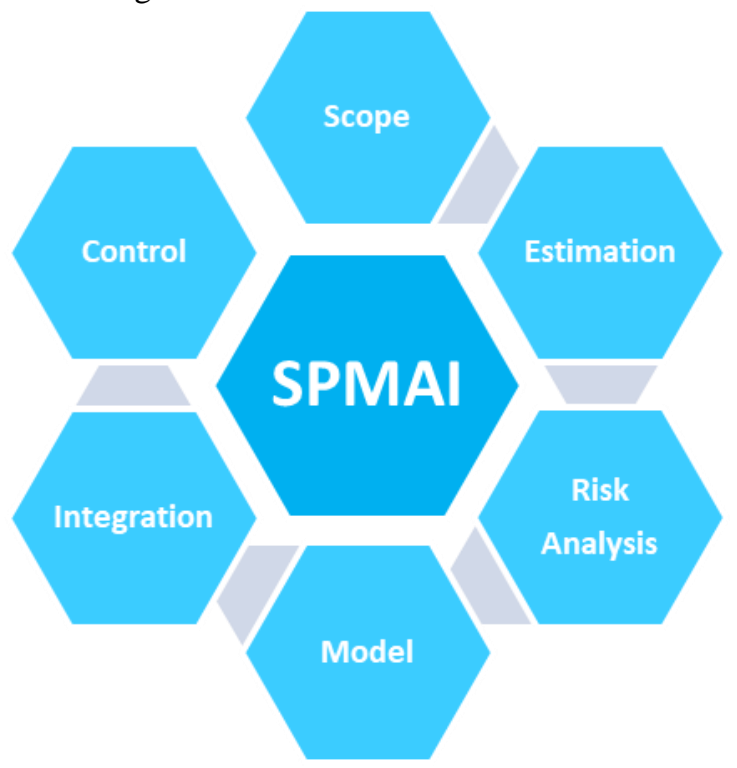

Fig. 1.Key parameters of SPM and AI.

The implementation of AI for the success of project can be conceptualized focusing on the traditional and present research on AI which will facilitate organizations to grasp a way to implement AI in SPM. The biggest issue with project management is poor support from top management in the organization. They are less attentive towards the goal of organization and projects that are associated with goal of organization. That's the main reason for involvement of AI to remind and notify them about to take an action at each stage of project development and management. Project management frameworks and knowledge bodies of project management define supported tools for control and monitoring ${ }^{[5]}$. Traditional parametrical tools are not enough for this purpose. However, several traditional tools have ignored some essential qualitative parameters of project management and consideration of all the stakeholders' point of view prior to development ${ }^{[14]}$. A project has been, categorized as successful if it accomplished its main concepts: Scope, and budget ${ }^{[13]}$. From the basic study we can easily conclude that concepts of project success can be differentiated, by the traditional Triple Constraint like scope, schedule, budget and quality and by focusing on processes of project management. On the other hand, criteria are more important for the success of the project from the resulting product point of view. Outi [41] surveyed that research communities are using AI techniques rather than software engineering practices for their software design. This research paper has merely focus on those Artificial Intelligence techniques that are used for successful estimation of projects and identification of critical factors of a project. 


\section{Business Process Reengineering: A Scope of Automation In Software Project Management using Artificial Intelligence}

To carry out at some level of outcome, an unstructured search is followed at initial level just to identify several different approaches and goals in the field of artificial intelligence applicable to project management. By considering of all stakeholder in project requirement analysis, project can be managed properly can meet with the stakeholders' expectations ${ }^{[8-9]}$. The success or failure of the project is merely dependent on input of stakeholder that has not been considered and this is the main reasons why projects goes failed or not get success as expected ${ }^{[10-12]}$. Littlewood ${ }^{[38]}$ et al analyzed probabilistic AI technique can be highly applicable in SEM like software model reliability using Bayesian model. Gingnell ${ }^{[39]}$ represented a joint probability distribution which the best suited method for data classification in different categories. While Horvitz et al ${ }^{[40]}$ analyzed that inherently needful elements of probability of stochastic nature of human behavior can help in probabilistic reasoning using Bayesian model.

\section{REVIEWS AND DISCUSSIONS}

Over all $60 \%$ of the software development projects are recognized as failed by the respondents who have been a part of SPM. With involvement of wider team in the project it become essential, a knowledge of how to engage stakeholders to bring better results. In the coming years, fundamental shift in collaboration in project management will be found. Now a change management has become an essential part of software process improvements for project managers. Collaboration between stakeholders at workplace on projects has becoming very essential for the success of the project. Collaborative nature of project management holds utmost importance in software development teams. Most of the software product and project managers have fear about the unsuccessful implementation and failure of the project.

Software system Development Life Cycle (SDLC) is vision employed in software system and engineering to explain a procedure for coming up with, developing, testing, and implementation of user demand specification. Software system engineers ought to follow SDLC phases for making well designed wares for users and should issues on issue poignant software system quality. Reengineering will invent a major amendment in product and service necessities, a major amendment in controls or constraints obligatory on a business method, or a major amendment within the technological platform that supports the organizational methods. Implementation of a reengineering initiative sometimes has wide impacts across structure boundaries, in addition as impacts on suppliers and customers ${ }^{[25]}$.

The main challenge of software project management is to accomplish all objectives of project as per specifications in the pioneer structure of information PMBOK ${ }^{[4]}$, PRINCE2 and ISO21500. Good knowledge and understating about problem definition and its resolution to achieve organizational goal is key to success towered projects with the help of better project management ${ }^{[3]}$. Some crucial parameters are known within the project development and management literature study is as follows:

- Software projects have perpetually been wounded by issues, ambiguities, bugs and continuous enhancements that build it very terribly onerous for project managers to arrange and schedules all resources and budgets ${ }^{[20-23]}$.
- Not only project managers and its team but all types of stakeholders, involved in software project management, are responsible for outcome of the project ${ }^{[16-19]}$.

- Fundamentally, software projects are covered by many uncertain complexities [7], which are becoming additional more and more critical everyday ${ }^{[15]}$.

The key parameters and variables to determine the success of the software project are: customer feedback, performance, selection of technologies, organizational support and structure. ${ }^{\text {[26-27] }}$. Coulin et al. ${ }^{\text {[31] }}$ proposed an automation tool MUSTER that can help in addressing issues with elicitation software development processes and improve requirement efficiencies with the help of intelligent technologies. Harman ${ }^{\text {[32] }}$ explored relationship between challenges for areas of AI and SEM. Technological areas has been changing very rapidly with the high expectation of improvement in technological management areas. As software engineers have been facing poorly defined application domains consistently changing and conflicting objectives, it has become very essential to upgrade SEM with the help of AI. Gelly et al ${ }^{\text {[33] }}$ analyzed and presented that since a decade AI algorithms have been contributing in software engineering areas to overcome insoluble challenges. Software development cost estimation is a very critical process for the project planning. Idri et al ${ }^{[34]}$ and Mair et al ${ }^{[35]}$ interpreted that ANN (Artificial Neural Network) is one of case reasoning based protocol helps in accurate cost estimation. ANN is an algorithm of Machine Learning (ML), which is a key domain area of AI. Maedche et al ${ }^{[36]}$ and Challagulla et al ${ }^{[37]}$ concluded that Ontology learning and defect prediction also helps in better prediction. Ranjith et al ${ }^{[24]}$ focused on implementation of automation in software business process management and determined several factors for success and failure of Robotic Process Automation (RPA) by conducting qualitative research methodology using surveys and interviews of engineers having experience of implementation of RPA in software development organization.

\section{CONCLUSION}

The change management is extremely essential in software engineering management. Managerial human parameters will efficiently influence the execution and implementation BPR (Business Process Reengineering) and acceptance of software system improvement methodologies. As a result of analysis of evolution of 'what can be the next' with the goal of distinctive attainable areas for improvement ought to incorporate the effectiveness factors. We evaluated that a significant rise of Artificial Intelligence (AI) has enabled a way to potential transformation for the business process re-engineering for software development organization. AI will be the potential game changer for the software project management and development life cycle processes. There is a huge demand of AI in all managerial areas of technology. AI can help project managers to focus on establishing organizational goals by cost optimization and improving quality of the product. The human intuition, feelings, ideas, emotions and passion cannot be consider or replaced by

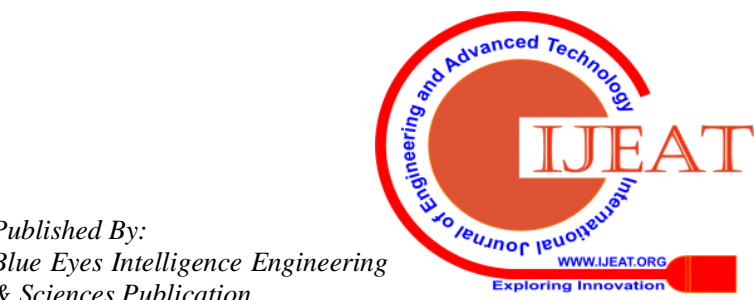


AI, so AI cannot be alternative of a project manager but will be helpful to project managers to optimizing the effort of the software project development and management team and in improving the significant level of the success of the project by eliminating repetitive operations from the project.

\section{FUTURE ENHANCEMENTS} literatures focusing on integration of AI with software engineering management and a scope of AI in software project development life cycle. There is a large scope of invention for successful implementation of AI in software project management for that we will continue this research in the next phases. At this stage a conceptual prototyping model requires with a strong protocol design that enables integration of Software Engineering Management with Artificial Intelligence. Further research work plan will be focus on enhancement in SDLC frameworks with more detail about how it can bring business process reengineering in the structure of software development organization. We, Krunal et al have concluded that BPR has been enabling organizational capabilities towards implementation of new initiatives with fewer complexities ${ }^{[30]}$. It just requires a PLCF - Process Life Cycle Method suitable to organizational structure. With this research are trying to conceptualize integration of AI with PLCF for software development organization.

\section{ACKNOWLEDGEMENT}

As a part of my academic affiliation with Indus University, through this research study we have tried to recognize the gap between the standard practice of applying AI techniques to the software engineering processes and software engineering management standard practices. A design of AI based standard framework is required that can be integrated with software engineering management process life cycles and it will be our next goal.

\section{ABBREVIATIONS}

A

$$
\begin{aligned}
& \text { AI - Artificial Intelligence } \\
& \text { ANN - Artificial Neutral Network }
\end{aligned}
$$

B

BPR - Business Process Reengineering

BPM - Business Process Management

D

$\mathbf{M}$

DL - Deep Learning

ML - Machine Learning

$\mathbf{N}$

NLP - Natural Language Processing

$\mathbf{R}$

PLCF - Process Life cycle Framework

RI - Risk Identification

RA - Risk Assessment

RPA - Robotic Process Automation

$\mathrm{S}$

SDLC - Software Development Life Cycle

SE - Software Engineering
This paper represents the analytical reviews of various

SEM - Software Engineering Management

SPI - Software Process Improvement

SPM - Software Project Management

SR - Speech Recognizer

\section{REFERENCES}

1. Hammer, M. and Champy. J., 1993, "Reengineering the Corporation: A Manifesto for Business Revolution", Harper Business Press, New York.

2. Joshi, C. S. and Dangwal, P. G., 2012, "Management of business process reengineering projects: A case study", Journal of Project, Program \& Portfolio Management, vol 3, no 1, pp. 78 - 89

3. Pinto, J. K. and Prescott, J. E., 1988, "Variations in Critical Success Factors over the Stages in the Project Life Cycle", Journal of Management, vol. 14, no. 1, pp. 05-18, doi: 10.1177/014920638801400102.

4. Project Management Institute - PMI, 2013, A Guide to Project Management Knowledge Body, The PMBOK Guide, 5th Edition.

5. Murray, A., Bennett, N. and Bentley, C., 2009, "Managing successful projects with PRINCE2", 2009 edition. London: The Stationery Office.

6. Glass, R. L., 2005, "IT Failure Rates - 70\% or 10-15\%?", IEEE Software, vol. 22, no. 3, pp. 110-112.

7. Baccarini, D., 1999, "The logical framework method for defining project success", Project Management Journal, vol. 30, no. 4, pp. 25-32.

8. Shenhar, A. J., Levy, O. and Dvir, D., 1997, "Mapping the Dimensions of Project Success", Project Management Journal, vol. 28, no. 2, pp. 5-13.

9. Wit, A. de, 1988, "Measurement of project success", International Journal of Project Management, vol. 6, no. 3, pp. 164-170.

10.Cooke-Davies, T., 2002, "The 'Real' Success Factors on Projects", International Journal of Project Management, vol. 20, no. 3, pp 185-190.

11.Hyvari, I., 2006, "Success of projects in different organizational conditions", Project Management Journal, vol. 37, no. 4, pp. 31-42.

12.Shenhar, A. J.; Dvir, D.; Levy, O. and Maltz, A. C., 2001, "Project Success: A Multidimensional Strategic Concept", Long Range Planning, vol. 34, no. 6, pp. 699-725.

13.Pinto, J. K. and Slevin, D. P., 1988, "Critical success factors across the project life cycle", Project Management Journal, vol. 19, pp. 67-75.

14.Mantel, S. J. and J. K. Pinto, J. K. 1990, "The causes of project failure", IEEE Transactions on Engineering Management, vol. 37, no. 4, pp. 269-276.

15.Saynisch, M., 2010, "Beyond frontiers of traditional project management: An approach to evolutionary, self-organizational principles and the complexity theory-results of the research program", Project Management Journal, vol. 41, no. 2, pp. 21-37.

16.Davis, K., 2014, "Different stakeholder groups and their perceptions of project success", ScienceDirect, International Journal Project Management, vol. 32, no. 2, pp. 189-201.

17.Indelicato, G., 2012, "Project Management Metrics, KPIs, and Dashboards: A Guide to Measuring and Monitoring Project Performance", Project Management Journal, vol. 43, no. 2, pp. 102-102.

18.Wang, X. and Huang, J., 2006, "The relationships between key stakeholders' project performance and project success: Perceptions of Chinese construction supervising engineers", International Journal of Project Management, vol. 24, no. 3, pp. 253-260.

19.Piraquive, F. N. D.; Crespo, R. G. and García, V. H. M., 2015, "Analysis and Improvement of the Management of IT Projects", IEEE Latin America Transactions, vol. 13, no. 7, pp. 2366-2371.

20.Ika, L. A., 2009, "Project success as a topic in project management journals", Project Management Journal, vol. 40, no. 4, pp. 6-19.

21.Geraldi, J. G.; Lee-Kelley, L. and Kutsch, E., 2010, "The Titanic sunk, so what? Project manager response to unexpected events", International Journal of Project Management, vol. 28, no. 6, pp. 547-558.

22.Sauser, B.; Reilly, R. and Shenhar, A., 2009, "Why projects fail? How contingency theory can provide new insights-A comparative analysis of NASA's Mars Climate Orbiter loss", International Journal of Project Management, vol. 27, no. 7, pp. 665-679.

23.Geraldi, J. G. and Adlbrecht, G., 2007, "On faith, fact and interaction in projects", Project Management Journal, vol. 38, no. 1, pp. 32-44.

24.Chandra, R.; Phaneendra, H. D. and Kavyashree, R., 2019, "Robotic Process Automation of Oracle ERP (AP) Process Using Automation Anywhere Tool Software Solution", International Research Journal of Engineering and Management Studies (IRJEMS), vol. 3, no. 5.

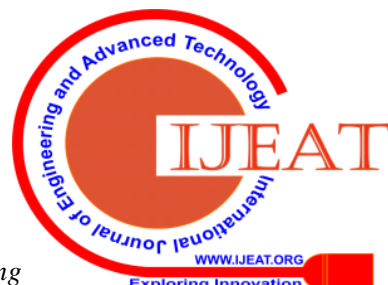


25.Stefanescu, A., 2008, "Business Intelligence - Improving Performance of Reengineering Project", University of Craiova, Faculty of Economics and Business, MPRA Paper No. 7793

26.Hyvari, I., 2006, "Success of projects in different organizational conditions", Project Management Journal, vol. 37, no. 4, pp. 31-42.

27.Kappelman, L. A.; Zhang, L. and McKeeman, R., 2006, "Early Warning Signs of it Project Failure: The Dominant Dozen", Information System Management, vol. 23, no. 4, pp. 31-36.

28.Dwivedi, S., 2016, "Software Development Life Cycle Models - A Comparative analysis", International Journal of Advanced Research in Computer and Communication Engineering, vol. 5, no. 2, pp. 232-233.

29.ISO/ICE/IEEE 12207:2017 System and Software Engineering - System Life Cycle Processes. International Organization for Standardization. November 2017.

30.Bhavsar K., Shah V. and Gopalan S., 2019, "Process Life Cycle Framework: A Conceptual Model and Literature Study of Business Process Re-Engineering for Software Engineering Management", vol. 11, no. 6, pp. 096-100, ISSN 0974-9748.

31.Coulin, C., Zowghi, D., \& Sahraoui, A., 2010, "MUSTER: A Situational Tool for Requirements Elicitation”, In F. Meziane, \& S. Vadera (Eds.), Artificial Intelligence Applications for Improved Software Engineering Development: New Prospects, pp. 146-165.

32.Harman, M., 2012, "The role of Artificial Intelligence in Software Engineering", First International Workshop on Realizing AI Synergies in Software Engineering (RAISE), Zurich, 2012, pp. 1-6. doi: 10.1109/RAISE.2012.6227961

33.Gelly, S., Kocsis, L., Schoenauer, M., Sebag, M., Silver, D., Szepesvari, C.' and Teytaud, O., 2012, "The grand challenge of computer Go: Mnote Caril tree search and extensions," Communications of the ACM, vol. 55, no. 3, pp. 106-113. doi: 10.1145/2093548.2093574

34.Idri, A., Khoshgoftaar, T. M. and Abran, A., 2002, "Can neural networks be easily interpreted in software cost estimation?" IEEE World Congress on Computational Intelligence. 2002 IEEE International Conference on Fuzzy Systems. FUZZ-IEEE'02. Proceedings (Cat No.02CH37291), Honolulu, HI, USA, vol. 2, pp. 1162-1167 doi: 10.1109/FUZZ.2002.1006668

35.Mair, C., Kadoda, G., Lefley, M., Phalp, K., Schofield, C., Shepperd, M. and Webster, S., 2000, "An investigation of machine learning based prediction systems," The Journal of Systems and Software, vol. 53, no. 1, pp. 23-29. doi: 10.1016/S0164-1212(00)00005-4

36.Maedche, A. and Staab, S., 2001, "Ontology learning for the semantic web", IEEE Intelligent Systems, vol. 16, no. 2, pp. 72-79, 2001. doi: 10.1109/5254.920602

37.Challagulla, V. U. B., Bastani, F. B., Yen, I. L., and Paul, R. A., 2005, "Empirical assessment of machine learning based software defect prediction techniques," 10th IEEE International Workshop on Object-Oriented Real-Time Dependable Systems, Sedona, Arizona, USA, 2005, pp. 263-270. doi: 10.1109/WORDS.2005.32

38.Littlewood, B. and Verrall, J. L., 1973, "A Bayesian reliability growth model for computer software", Applied Statistics, vol. 22, no. 3, pp. 332-346. doi: 10.2307/2346781

39.Gingnell, L.; Franke, U.; Lagerström, R.; Ericsson, E. and Lilliesköld, J., 2014, "Quantifying Success Factors for IT Projects-An Expert-Based Bayesian Model," Information System Management, vol. 31, no. 1, pp. 21-36.

40.Horvitz, E.; Breese, J.; Heckerman, D.; Hovel, D. and Rommelse, K., 1998, "The Lumiere project: Bayesian user modeling for inferring the goals and needs of software users", in Proceedings of the Fourteenth Conference on Uncertainty in Artificial Intelligence. San Mateo: Morgan Kaufmann, Jul. 1998, pp. 256-265

Räihä O., 2010, "A survey on search-based software design", Computer Science Review, vol. 4, no. 4, pp. 203-204, doi: 10.1016/j.cosrev.2010.06.001

\section{AUTHORS PROFILE}

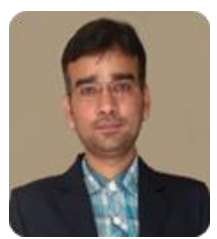

Krunal Bhavsar is a research scholar and corresponding author to this research paper. He is pursuing his $\mathrm{PhD}$ in the stream of Computer Science and Engineering at Indus University, Ahmedabad, India. Krunal has received his MBA in Information Technology from Indus University (Ahmedabad, India) in 2018 and MSc in Mobile Application and Technology from Gujarat University (Ahmedabad, India) in 2014 and BSc in Computer Science from Gujarat University (Ahmedabad, India) in 2012. He is an enthusiastic research scientist with $14+$ years of corporate experience in software business process management, software project management, software engineering and data analytics. He is a Technical Project Manager in software research and development organization. He has been serving as a visiting lecturer at Computer Science department at Gujarat University also. Teaching, Training, Learning are his hobbies and he is passionate about research and development.

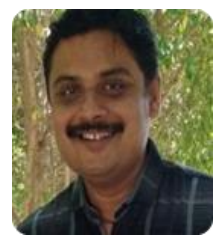

Dr. Vrutik Shah is a research guide and contributor author to this research paper. He has received his $\mathrm{PhD}$ from Karpagam University in the stream of Computer Science and MCA in the stream of Computer Application from Nirma University. He is a Technica Project Manager in multinational well-known software development organization - Streebo and he has been leading software process redesign and redevelopment with the help of trending automation technologies. He is a certified Agile Scrum Master and having expertise in software project and product management, business analysis and business process reengineering.

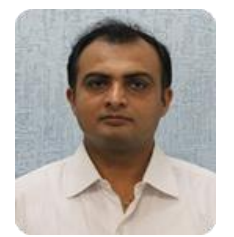

Dr. Samir Gopalan is a research co-guide and contributor author to this research paper. He is a director and a head of department of management, external relation manager and dean of faculty (OSD Research) at Indus University. He has achieved Ph.D., M.Phil. (Computer Science), MBA (Finance) and BSc degrees in his academic career. His domain research areas are marketing management, business intelligence, training \& development, skill \& performance enhancement with $15+$ years of experience. Krunal Bhavsar is the author to whom all the correspondence regarding this research paper should be addressed; E-mail: krunalbhavsar@engineer.com; krunalbhavsar.rs@indusuni.ac.in. Tel: +91-9737007007 